\title{
Detection and attribution of global change effects on river nutrient dynamics in a large Mediterranean basin
}

\author{
R. Aguilera ${ }^{1}$, R. Marcé $^{1}$, and S. Sabater ${ }^{1,2}$ \\ ${ }^{1}$ Catalan Institute for Water Research (ICRA), Scientific and Technological Park of the University of Girona, \\ Emili Grahit 101, 17003 Girona, Spain \\ ${ }^{2}$ Institute of Aquatic Ecology, University of Girona, Faculty of Sciences, Campus Montivili, 17071 Girona, Spain \\ Correspondence to: R. Aguilera (raguilera@icra.cat)
}

Received: 19 January 2015 - Published in Biogeosciences Discuss.: 02 April 2015

Revised: 25 June 2015 - Accepted: 25 June 2015 - Published: 07 July 2015

\begin{abstract}
Attributing changes in river water quality to specific factors is challenging because multiple factors act at different temporal and spatial scales, and it often requires examining long-term series of continuous data. Data consistency is sometimes hindered by the lack of observations of relevant water quality variables and the low and uneven sampling frequency that characterizes many water quality monitoring schemes. Nitrate and dissolved phosphate concentration time series (1980-2011) from 50 sampling stations across a large Mediterranean river basin were analyzed to disentangle the role of hydrology, land-use practices, and global climatic phenomena on the observed nutrient patterns, with the final aim of understanding how the different aspects of global change affected nutrient dynamics in the basin. Dynamic factor analysis (DFA) provided the methodological framework to extract underlying common patterns in nutrient time series with missing observations. Using complementary methods such as frequency and trend analyses, we sought to further characterize the common patterns and identify the drivers behind their variability across time and space. Seasonal and other cyclic patterns were identified as well as trends of increase or decrease of nutrient concentration in particular areas of the basin. Overall, the impact of global change, which includes both climate change and anthropogenic impacts, on the dynamics of nitrate concentration across the study basin was found to be a multifaceted process including regional and global factors, such as climatic oscillations and agricultural irrigation practices, whereas impacts on phosphate concentration seemed to depend more on local impacts, such as urban and industrial activities, and less on large-scale factors.
\end{abstract}

\section{Introduction}

The Earth system is intrinsically dynamic but the intensity and rate of recent environmental changes are overall unprecedented (Meybeck, 2003; García-Ruiz et al., 2011). Land-use change and management practices, pollution, human demography shifts, and climate change are components of global environmental change (Rosenzweig et al., 2008), understood as the synergy between climate change and direct action of human activities on the territory (US Global Change Research Act, 1990). Freshwaters are at the forefront of the phenomena associated with global change (Vörösmarty et al., 2010), and impacts on water resources availability as well as on their quality are extensive (Parmesan and Yohe, 2003; Milly et al., 2005; Grimm et al., 2008; Rabalais et al., 2009; Gallart et al., 2011).

Nutrient pollution derived from anthropogenic activities impacts inland and coastal waters, resulting in serious environmental and human health issues and impacting the economy (Howarth et al., 2002; Woodward et al., 2012). A fundamental concern in river ecology is therefore to understand the spatial patterns of nutrient concentration and loading in rivers, their variation during the last decades, and whether these are promoted by the increasing human activities (Grizzetti et al., 2011) or associated with climate change (Marcé et al., 2010). This is particularly relevant in Mediterranean regions where the imbalance between available water resources and increased demands has become a growing problem (Milly et al., 2005; Bovolo et al., 2011) and where streams and rivers bear concurrent additional pressures such as damming, water extraction, and urbanization (Sabater 
and Tockner, 2010). In Spain, for instance, the construction rate of large dams peaked during the 1960s and 1970s, whereas human population density and urban area in the Mediterranean region increased during the 1990s (Cooper et al., 2013). Furthermore, nutrient pollution in Mediterranean rivers contributes to eutrophication because of the coexistence of naturally occurring low flows and high water demand (Caille et al., 2012). However, it is challenging to attribute changes in nutrient concentration dynamics to specific factors, because factors of change exist and act at different temporal and spatial scales (Kundzewicz and Krysanova, 2010). Identifying factors and causes often requires examining long-term series of data, which should be consistent and of good quality. Such detailed analysis, which aims to extract the key properties enclosed in time series, is essential to obtain insight of the physical, biological, or socioeconomic events and associated impacts that originally shaped these time series (Ghil et al., 2002). It is realistic to consider that temporal trends and spatial patterns reveal emerging environmental problems (Lane et al., 1994; Lovett et al., 2007; Marcé et al., 2010; Estrada et al., 2013). Data consistency can, however, be affected by the lack of observations of relevant water quality variables and the low or uneven sampling frequency, which are common characteristics of many water quality monitoring schemes worldwide. These impede the appropriate analysis of the time series available from longterm monitoring, eventually affecting management decisions on the minimization of effects of global change particularly in Mediterranean regions, where there is a dearth of knowledge compared to other temperate regions (Benítez-Gilabert et al., 2010). The vast majority of studies of global change impact based on the analysis of long-term data use time series methods like the Mann-Kendall and the seasonal Kendall analyses for trend detection (Chang, 2008; Bouza-Deaño et al., 2008; Argerich et al., 2013), wavelet analysis for temporal patterns (Kang and Lin, 2007), combinations of statistical models such as univariate and multivariate regressions (Tilman et al., 2001), and analysis of variance and variography (i.e., spatial dependence measured as a function of the distance and direction separating two locations; Bernal et al., 2013). Spectral analysis (e.g., singular spectrum analysis), is limited to characterizing the spectral density to detect any periodicities in the data and does not necessarily allow the identification of common patterns embedded in a collection of time series (Zuur et al., 2003). Furthermore, most of the above-mentioned methods do not easily accommodate missing observations, which are extremely abundant in most public environmental databases. The restrictions on the number of time series that can be analyzed and the requirements of continuous time series needed to implement such methods make the analysis of water quality data sets in large regions difficult and cumbersome. Since in most occasions the impact of global change on a given ecosystem consists of the overlap of multiple stressors acting at both regional and local scales, it is necessary to use methodologies that explicitly consider the inextricable link between temporal and spatial patterns of change and that are able to accommodate missing values. We use a combination of dynamic factor analysis (DFA), classical time series methods, and spatial regression models to extract underlying common patterns in a set of time series and to depict their relationships with local and global-scale phenomena. We apply the above to a set of river nutrient concentration time series within a Mediterranean basin in order to identify temporal and spatial patterns at the basin-wide scale and to understand how global change shapes these patterns. Both nitrate and dissolved phosphate dynamics were analyzed in order to disentangle the role of hydrology, land-use practices, and climate phenomena on the observed patterns, with the final aim of understanding how the different aspects of global change may affect nutrient variability (and hence water quality) in the basin.

\section{Study area}

The Ebro River is one of the main tributaries of the Mediterranean Sea. The mean annual runoff at the outlet is $13408 \mathrm{hm}^{3}$. The basin covers a highly heterogeneous area of ca. $85500 \mathrm{~km}^{2}$, which extends from the southern-facing side of the Cantabrian range and Pyrenees and the northernfacing side of the Iberian Massif until the river reaches the Mediterranean Sea (Sabater et al., 2009). The geographical setting of the Ebro River determines a large range of climatic conditions (Sabater et al., 2009). Mean annual precipitation varies from over $2000 \mathrm{~mm}$ in the Pyrenees to less than $400 \mathrm{~mm}$ in the arid interior. Overall, silicic materials are located in the uppermost altitudes while calcareous materials occur at lower elevations (Lassaletta et al., 2009). The water biogeochemical characteristics are highly influenced by anthropogenic activities. The main effects are those due to water discharge regulation (i.e., the construction of large reservoirs) and agriculture (determining increases in nitrate concentration) (Romaní et al., 2010). The intense use of water throughout the basin (Boithias et al., 2014) puts the Ebro River under strong pressure particularly in the most downstream sections during dry annual periods, when irrigation is widespread. The basin started a sanitation plan during the 1990s that progressively covered most of the local inputs.

\section{Materials and methods}

\subsection{Time series data}

Existing nitrate and phosphate concentration as well as water discharge data of the Ebro River basin were collected from public databases (Ebro Basin Authority, CHE). The frequency of sampling was monthly. We selected 50 monitoring points distributed all across the basin that showed the longest time series, consisting of 31-year-long (1980-2011) monthly data. Thus, these time series had a maximum length of 372 
data points, although most of the stations contained observation gaps. Outliers, related mainly to recording errors, were manually removed considering expected ranges of values for each nutrient. Discharge time series were available in 37 of the sampling sites.

\subsection{Detection and attribution of global change effects: methodological steps}

The first step in defining global change effects on nutrient time series was to detect common temporal patterns (i.e., cycles and trends) (Sect. 3.3) in the 50 nutrient time series (nitrate or phosphate) using dynamic factor analysis (Zuur et al., 2003). Once the common patterns for nitrate and phosphate were identified, we described the significant cycles and trends present in those patterns with classical frequency (Sect. 3.4) and trend (Sect. 3.5) analyses. Subsequently, the potential dependence on hydrological variability was sought by exploring any significant association between patterns and water discharge time series (Sect. 3.6). We finally assessed the spatial variability of these patterns and their relationship to environmental change drivers in the region by means of spatial regression models (Sect. 3.7) and clustering (Sect. 3.8).

\subsection{Extraction of common nutrient concentration patterns}

DFA (Zuur et al., 2003) is a dimension-reduction method that estimates underlying common patterns in a set of time series. It is based in the so-called state-space model, which treats each observed time series as a linear combination of multiple state processes (Holmes et al., 2012). A considerable advantage of the state-space approach is the ease with which missing observations can be dealt with. The main disadvantage of DFA is that it can be computationally expensive. DFA decomposes the observed time series from all sampling points included in the analysis into common patterns and their associated error terms (Holmes et al., 2012). The resulting patterns are in turn related to factor loadings, which indicate the weight that each pattern has at every monitoring point included in the analysis. In other words, DFA models the different time series as a linear combination of common temporal patterns in a similar way that a principal component analysis reduces an $n$-dimensional problem into a few manageable axes. Both the identified common patterns and their relevance at each sampling point (i.e., the factor loadings) were subsequently analyzed using additional time series and regression techniques. DFA was applied to our database by means of the MARSS v3.4 R package (Holmes et al., 2013). We also used DFA to enhance the signal-tonoise ratio of the measured streamflow time series which in turn facilitated the identification of characteristic oscillations and potential relationships between streamflow and other variables. After DFA, we reconstructed the streamflow time series at each sampling point (since the original time series contained missing observations) using the best linear combination of the common patterns identified during DFA. This procedure is equivalent to other signal-to-noise ratio enhancement methods, like reconstruction using singular spectrum analysis (Ghil et al., 2002), with the difference that our approach enhances the features shared by the different time series.

\subsection{Identification of significant oscillations in the common nutrient concentration patterns}

We analyzed all significant frequencies present in the common patterns identified by DFA using frequency analysis. We specifically aimed to identify frequencies that could be linked to seasonal cycles (6 and 12 months period) and climatic interannual oscillations. We chose the multitaper method (MTM) due to its reduced variance of spectral estimates compared to classical methods (Ghil et al., 2002). Frequencies significantly different from noise at the $p<0.05$ level were identified using the $F$ test for spectral frequencies. MTM was applied using the multitaper $\mathrm{R}$ package (Rahim and Burr, 2013).

\subsection{Identification of significant temporal trends in the common nutrient concentration patterns}

Since the common patterns are allowed to be stochastic in DFA, they can also contain significant trends that are nonlinear (Zuur et al., 2007). We therefore sought to identify the significant trends present in individual patterns and to characterize such trends as increasing or decreasing over time. We used the implementation of the Yue-Pilon (Yue et al., 2002) prewhitening approach included in the zyp $R$ package (Rahim and Burr, 2013) to determine the trends in data that are serially correlated. The method computes both the Kendall tau statistic and the Kendall $p$ value.

\subsection{Relationships between streamflow and the common nutrient concentration patterns}

The relationships between streamflow and nitrate and phosphate concentration patterns from the DFA analysis were assessed with the maximal information coefficient (MIC) method (Reshef et al., 2011), which belongs to a larger family of statistics called Maximal Information-based Nonparametric Exploration (MINE; http://www.exploredata.net/). MIC captures a wide range of associations which are not restricted to be linear, without the need to define a model a priori. MIC provides a score that roughly corresponds to the coefficient of determination of the data relative to the regression function as well as a significance level. In our case, we calculated MIC scores and significance levels for each paired combination of common nutrient concentration patterns and the DFA reconstructed streamflow series measured at each sampling station. We used these filtered streamflow time se- 
ries instead of the original ones due to the continuity of the resulting filtered series and in order to enhance the signal-tonoise ratio.

\subsection{Attribution of drivers for spatiotemporal variability of the common nutrient concentration patterns}

Factor loadings are the multiplication factors that determine the linear combination of the common patterns to produce a best-fit nutrient concentration time series (Zuur et al., 2003). Factor loadings can take positive or negative values when specific time series behave in an opposite way to that described by the extracted pattern. Therefore, the geographical distribution of factor loading values across monitoring points inform about the spatial development of the processes responsible for the extracted patterns. To evaluate the relationship between the relevance (i.e., factor loading) of the extracted patterns at each sampling point and the environmental change drivers, we selected a set of potential explanatory variables that were spatially distributed. These included meteorological variables (mean annual air temperature and precipitation), reservoir capacity and location, wastewater treatment plants (WWTP) discharge and location, specific streamflow (runoff index), mean river nutrient concentration in the sampling point, land-use distribution, and five variables related to nitrogen loads and their sources obtained by (Lassaletta et al., 2012): application of synthetic fertilizers, application of manure, inputs by biological fixation, total exported N, and point sources. The land-use conditions included in our study represent the average conditions between the period 1980 to 2011 when no other significant or drastic land-use changes occur other than management practices related to the improvement of industrial and urban wastewater, which are reflected in the decrease of phosphate in 1990s.

For each sampling point we calculated mean values or percent areas of all the above explanatory variables considering two different regions. The first included a buffer area of $10 \mathrm{~km}$ surrounding the point, aimed at capturing the more local conditions. In the case of reservoirs and WWTP, this represented the immediate upstream potential effects of these variables on individual sampling points. The second region included the total basin upstream from the sampling point. The total basin area was excluded from the explanatory variables analyses as it was highly collinear with the variables calculated for the basin upstream area of each sampling point.

The potential explanatory variables were related to factor loadings measured at each sampling site by the generalized least squares (GLS) regression model (Pinheiro and Bates, 2000). The use of generalized least squares for regression modeling is advisable when neighboring values of the response variable tend to be spatially correlated (Pinheiro and Bates, 2000). The GLS models were fitted using the nlme R package (Pinheiro et al., 2012). In our case, we assumed a spatial error structure using the Gaussian distribution available in nlme, since it provided the best model results based on Akaike information criterion (AIC) values. A combination of forward and backward selection was used to identify the significant explanatory variables, using the AIC criterion to identify the best model. We fitted different GLS models for sampling stations showing opposite signs of the factor loading for a given pattern (e.g., stations showing positive and negative factor loadings for Pattern 1 of nitrate concentration were treated separately). The rationale of this procedure is that many fundamental features of the patterns (phase of the time series, relationships with streamflow and other variables, direction of the trends) change when the pattern is flipped due to a change of the factor loading sign, potentially implying different generating mechanisms.. In order to assess the model fit and the variance explained, we calculated a generalized R-squared based on Cox and Snell (1989) using the r.squaredLR function included in the MuMIn R package (Barton, 2014).

\subsection{Spatial aggregation of common nutrient concentration patterns and explanatory variables}

We assessed the clustering of the spatial distribution of nutrient concentration patterns and the significant explanatory variables found in GLS regression models. We used the clustering analysis to portray homogeneous regions in terms of the presence of concrete nutrient concentration patterns and their likely drivers. Our final aim was to highlight the most relevant cause-effect mechanisms that define vulnerable regions to the effects of global change. We used the implementation of the unsupervised $k$-means algorithm in the open source data visualization and analysis tool Orange 2.7 (http://new.orange.biolab.si/), which uses the betweencluster-distances score to assess the most effective grouping. The method looks for a solution where all the features (in our case, the value of all factor loadings and significant explanatory variables found during GLS modeling) within each group are as similar as possible, and all the groups themselves are as different as possible. Thus, it is not necessary to define the number of desired cluster beforehand. We applied the $k$-means algorithm without any spatial constraints. Although explicit spatial relationships actually exist between sampling points along a river network, our aim was to identify clusters exclusively based on the information contained in the factor loadings and explanatory variables.

\section{Results}

\subsection{Common nutrient concentration patterns in the basin}

The DFA analysis for nitrate concentration extracted three common patterns from the set of 50 time series (Fig. 1a), where the order of the extracted patterns has no implication 
Table 1. Characterization of the temporal variability and relationships with streamflow of nutrient patterns detected with DFA in the Ebro basin.

\begin{tabular}{|c|c|c|c|c|}
\hline Nutrient & $\begin{array}{l}\text { Trend } \\
\text { (Kendall } \\
\text { tau) }\end{array}$ & $\begin{array}{l}\text { Significant } \\
\text { oscillations } \\
\text { (years) }\end{array}$ & $\begin{array}{l}\text { Significant } \\
\text { MINE } \\
\text { relationships } \\
\text { with streamflow } \\
\text { (number of sites } \\
\text { out of 37) }\end{array}$ & $\begin{array}{l}\text { Other relationships } \\
\text { with streamflow }\end{array}$ \\
\hline \multicolumn{5}{|l|}{ Nitrate } \\
\hline Pattern 1 & ns & 1 and 2.6 & 34 & $\begin{array}{l}\text { - Strong seasonal coherence (Fig. 1e) } \\
\text { - Coincident and significant streamflow } \\
\text { oscillation at } 2.2 \text { years }\end{array}$ \\
\hline Pattern 2 & ns & 1 & 12 & - Nothing to remark \\
\hline Pattern 3 & $-0.53^{c}$ & 3.5 & 22 & $\begin{array}{l}\text { - } \quad \text { Trend NOT related to streamflow } \\
\text { - } \quad \text { Coincident and significant streamflow } \\
\text { oscillation at } 3.2 \text { years }\end{array}$ \\
\hline \multicolumn{5}{|l|}{ Phosphate } \\
\hline Pattern 1 & ns & 1 & 2 & - Moderate seasonal coherence (Fig. 1g) \\
\hline Pattern 2 & $-0.09^{\mathrm{b}}$ & ns & 4 & - $\quad$ Trend NOT related to streamflow \\
\hline Pattern 3 & ns & 1.6 and 4.3 & 25 & $\begin{array}{l}\text { - Coincident and significant streamflow } \\
\text { oscillations at } 1.5 \text { and } 4.2 \text { years }\end{array}$ \\
\hline Pattern 4 & $-0.08^{\mathrm{a}}$ & ns & 10 & - $\quad$ Trend NOT related to streamflow \\
\hline
\end{tabular}

a: $p<0.05 ;{ }^{\text {b }}: p<0.01{ }^{\mathrm{c}}: p<0.001$

on the importance or weight of a particular pattern. Patterns 1 and 2 identified in nitrate time series had a marked seasonal component appreciated visually (Fig. 1a) and further confirmed by the significant 12 month cycles found in the frequency analysis (Table 1). The seasonal evolution of Pattern 1 was clearly associated with the seasonal streamflow pattern (Fig. 1e), suggesting that it was hydrology driven. The MINE analysis also detected significant associations between Pattern 1 of nitrate concentration and the DFA reconstructed streamflow series in almost all sites across the basin (Table 1). Nitrate concentration increased with streamflow (sites showing positive factor loadings) and was affected by a dilution dynamics (negative factor loadings). In contrast, Pattern 2 was strongly associated with the seasonal evolution of the mean air temperature in the basin (Fig. 1f), suggesting its connection to phenological processes (lower values during the growing season). Pattern 1 of nitrate concentration was also associated with a ca. 2.6-year periodicity according to the MTM analysis, and Pattern 3 showed a significant 3.5-year oscillation period (Table 1). Pattern 3 also included a significant decreasing trend (Table 1). The signs associated with DFA factor loadings of Pattern 3 indicated that 20 of the 50 stations were in fact following the opposite trend. The significance or relevance of this opposite decreasing trend in nitrate concentration is indicated by the magnitude of the factor loadings in those 20 stations (shown in Fig. 2).

DFA extracted four common patterns from the 50 dissolved phosphate concentration time series included in the analysis (Fig. 1b). The 1990s represented a shift-time point for phosphate patterns. In all four patterns, a sharp decrease in the phosphate concentration occurred in the early 1990s, and shifted to a steady behavior until the end of the study period, but the four patterns differed in peak timing before the 1990s. Despite the overall decrease (also observed in phosphate flux in upstream and downstream locations; Sect. S.1. of Supplement), only Pattern 2 had a highly significant trend while trend in Pattern 4 was only marginally significant (Table 1). Pattern 1 had a marked seasonal cycle, potentially driven by streamflow (suggested by the significant relationship between the seasonal evolution of the pattern and streamflow; Fig. 1b). However, the MINE algorithm detected just two significant associations between this pattern and the DFA reconstructed streamflow time series from the sampling sites (Table 1). Pattern 3 showed cycles of ca. 4.3 and 1.6 years (Table 1). The frequency analysis of the 37 DFA reconstructed streamflow series revealed several characteristic oscillations. Apart from the strong seasonal signal, there were significant oscillations at 1.5, 2.2, 3.2, 4.2, and 9 years in several sampling stations. Periods from 1.5 to 4.2 years were highly coherent with the oscillations found in the common patterns of nitrate and phosphate concentration (Table 1), suggesting that multiyear oscillations in nutrients concentration were related to streamflow variability. Interestingly, nitrate and phosphate patterns showing at least one significant oscillation with period longer than 1 year also showed many significant MINE associations with streamflow across sites (Table 1). No significant trend was detected in the 
Table 2. GLS resulting potential drivers involved in the spatiotemporal variability of nitrate patterns in the Ebro basin.

\begin{tabular}{|c|c|c|c|c|c|c|}
\hline Nitrate patterns & $\begin{array}{l}\text { Pseudo } \\
R^{2}\end{array}$ & Explanatory variable & Coefficient & $\begin{array}{l}\text { Std. } \\
\text { error }\end{array}$ & $t$ value & $p$ value \\
\hline Pattern 1 - & 0.65 & Mean air temperature $\left({ }^{\circ} \mathrm{C}\right)$ UPSTREAM & -1.42 & 0.30 & -4.66 & 0.0001 \\
\hline \multirow[t]{3}{*}{ Positive factor loadings } & & Water area $\left(\mathrm{km}^{2}\right)$ UPSTREAM & 0.06 & 0.00 & 13.75 & 0.0000 \\
\hline & & Dryland farming $(\%)$ LOCAL & 0.00 & 0.00 & 3.23 & 0.0035 \\
\hline & & Industrial area (\%) UPSTREAM & -0.12 & 0.04 & -2.91 & 0.0074 \\
\hline Pattern 1 - & 0.61 & Reservoir capacity $\left(\mathrm{hm}^{3}\right)$ LOCAL & -0.05 & 0.02 & -2.64 & 0.0166 \\
\hline \multirow[t]{2}{*}{ Negative factor loadings } & & Irrigated agriculture area (\%)UPSTREAM & 0.30 & 0.05 & 6.37 & 0.0000 \\
\hline & & Mean annual precipitation (m) UPSTREAM & 0.48 & 0.11 & 4.42 & 0.0003 \\
\hline \multirow[t]{3}{*}{ Pattern 2} & 0.59 & Irrigated agriculture area $\left(\mathrm{km}^{2}\right)$ UPSTREAM & 0.11 & 0.01 & 19.06 & 0.0000 \\
\hline & & Irrigated agriculture area (\%) LOCAL & 0.00 & 0.00 & -2.59 & 0.0127 \\
\hline & & Mean daily precipitation (m) LOCAL & 0.16 & 0.07 & 2.29 & 0.0269 \\
\hline \multirow{2}{*}{$\begin{array}{l}\text { Pattern } 3 \text { - } \\
\text { Positive factor loadings }\end{array}$} & 0.57 & Industrial area (\%) UPSTREAM & 0.04 & 0.01 & 6.53 & 0.0000 \\
\hline & & Synthetic fertilizer load UPSTREAM & -0.01 & 0.00 & -3.45 & 0.0018 \\
\hline \multirow{3}{*}{$\begin{array}{l}\text { Pattern } 3 \text { - } \\
\text { Negative factor loadings }\end{array}$} & 0.56 & Industrial area (\%) UPSTREAM & 0.04 & 0.01 & 4.81 & 0.0001 \\
\hline & & Areal manure load UPSTREAM & 0.04 & 0.01 & 3.01 & 0.0063 \\
\hline & & Water area (\%) UPSTREAM & 0.01 & 0.01 & 2.14 & 0.0428 \\
\hline
\end{tabular}

Table 3. GLS resulting potential drivers explaining the spatiotemporal variability of phosphate patterns in the Ebro basin.

\begin{tabular}{|c|c|c|c|c|c|c|}
\hline Phosphate patterns & $\begin{array}{l}\text { Pseudo } \\
R^{2}\end{array}$ & Explanatory variable & Coefficient & Std. error & $t$ value & $p$ value \\
\hline Pattern 1 & 0.62 & $\begin{array}{l}\text { Synthetic fertilizer load UPSTREAM } \\
\text { Mean river phosphate concentration } \\
\text { Runoff index UPSTREAM } \\
\text { Industrial area (\%) UPSTREAM }\end{array}$ & $\begin{array}{l}0.46 \\
-0.07 \\
-0.03 \\
0.19\end{array}$ & $\begin{array}{l}0.08 \\
0.02 \\
0.01 \\
0.05\end{array}$ & $\begin{array}{l}6.18 \\
-3.97 \\
-3.69 \\
4.02\end{array}$ & $\begin{array}{l}0.0000 \\
0.0003 \\
0.0006 \\
0.0002\end{array}$ \\
\hline $\begin{array}{l}\text { Pattern } 2 \text { - } \\
\text { Positive factor loadings }\end{array}$ & 0.20 & Industrial area $\left(\mathrm{km}^{2}\right)$ UPSTREAM & 0.03 & 0.02 & 2.22 & 0.0384 \\
\hline $\begin{array}{l}\text { Pattern } 2 \text { - } \\
\text { Negative factor loadings }\end{array}$ & 0.17 & Grass and shrubland area (\%) LOCAL & 0.01 & 0.00 & 2.24 & 0.0339 \\
\hline Pattern 3 & 0.21 & Industrial area $\left(\mathrm{km}^{2}\right)$ UPSTREAM & 0.05 & 0.01 & 3.60 & 0.0008 \\
\hline Pattern 4 & 0.14 & Industrial area (\%) UPSTREAM & 0.05 & 0.02 & 2.75 & 0.0083 \\
\hline
\end{tabular}

streamflow series (extracted common DFA patterns shown in Sect. S.2 of the Supplement).

\subsection{Factors explaining the distribution of the different nutrient concentration patterns}

The GLS regression models for the distribution of factor loadings for each pattern identified several significant explanatory variables (Tables 2 and 3). Since nitrate concentration Patterns 1 and 2 showed contrasted positive and negative factor loadings across sites, we considered different models for sites showing positive and negative factor loadings. The distribution of positive factor loadings for Pattern 1 strongly related to the total area of water (mainly reservoirs). The higher the total area occupied by water upstream, the higher the weight of Pattern 1. Other associations were also significant, although their prediction weights on the model were less important: a negative relationship with mean annual air temperature upstream from the sampling point, a positive relationship with dryland farming area around the sampling point, and a negative association with the industrial areas upstream from the sampling point (Table 2). Negative factor loadings of Pattern 1 were related to the presence of irrigated agricultural lands and to the mean annual precipitation received upstream. The reservoir water capacity upstream the sampling point had a small and marginally significant effect.

Factor loadings for Pattern 2 of nitrate were strongly associated with sites with irrigated agricultural areas upstream from the sampling point. The distribution of Pattern 2 was also weakly related to the annual mean precipitation and the 

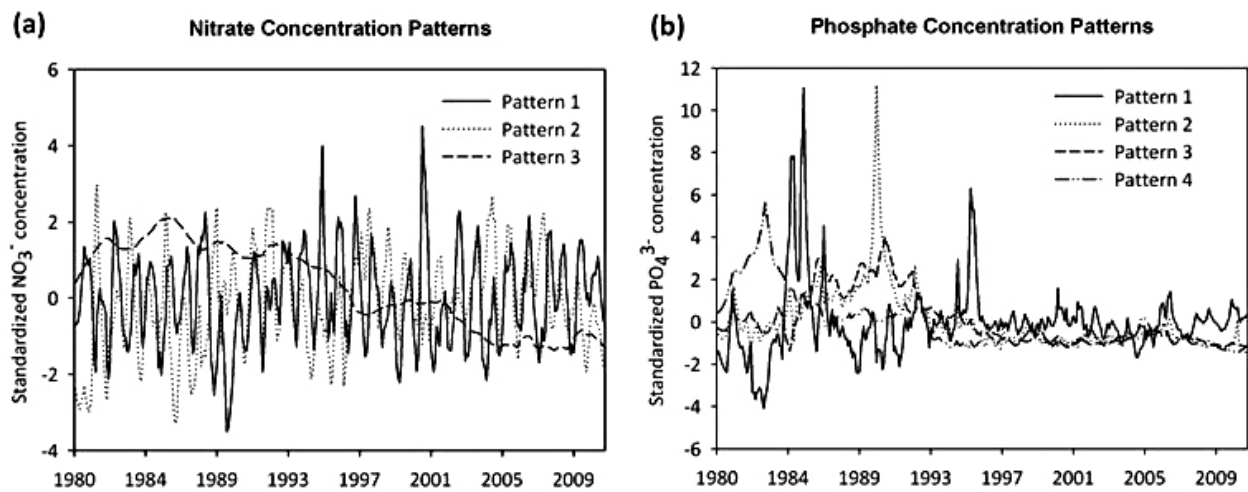

(c)

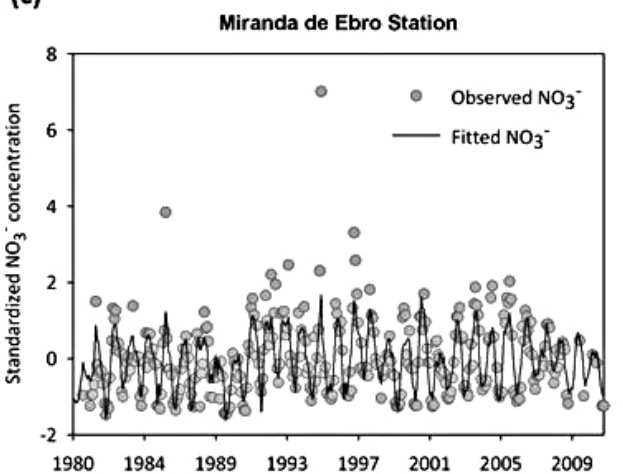

(d)
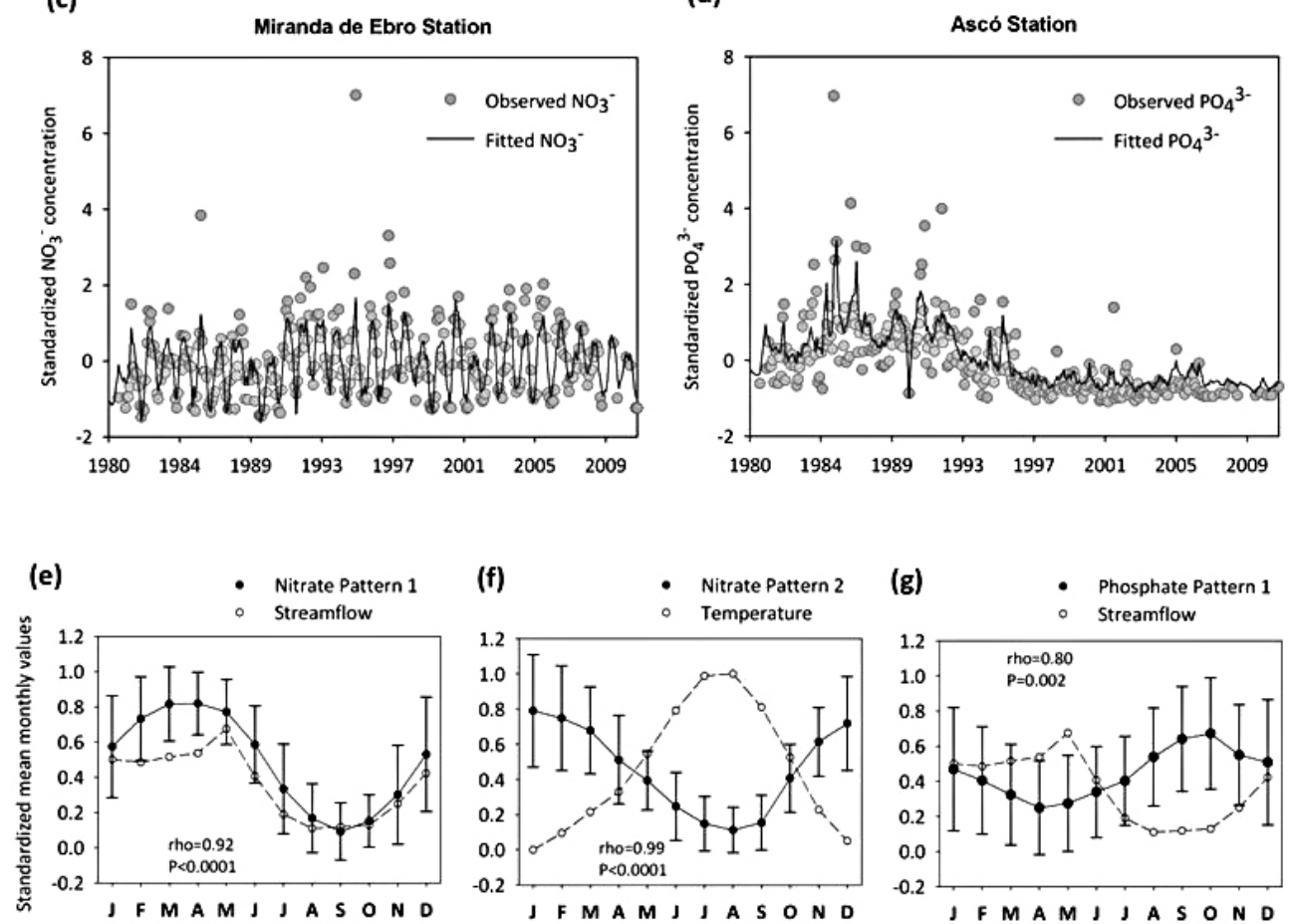

Figure 1. Top: DFA resulting patterns for nitrate (a) and phosphate (b) concentration. Middle: examples of observed time series and fitted DFA models at two selected monitoring points for nitrate (c) and phosphate (d) concentration. The DFA models in panels (c) and (d) are the result of a linear combination of the patterns in panels (a) and (b), respectively. Bottom: seasonal variation for nitrate Pattern 1 and streamflow (e), nitrate Pattern 2 and temperature (f), and phosphate Pattern 1 and streamflow (g). Points depict monthly averages for the entire 31-year time series. For temperature and streamflow, the average is for all time series available. We only included standard deviations as error bars for the nutrient patterns to enhance readability

presence of irrigated lands. Finally, the distribution of factor loading values for Pattern 3 was spatially associated with industrial areas. The main difference between models for negative and positive factor loadings for this pattern was dictated by the relevance of distinct sources of nitrogen being used in the area, namely, synthetic fertilizers and manure (Table 2). Globally, the explanatory power of the GLS models for the distribution of phosphate patterns was much lower than for nitrate concentration models (Table 3). Pseudo- $R^{2}$ values were one-third of those found in nitrate models except for Pattern 1, which reached similar explanatory power. The distribution of the factor loadings of Pattern 1 was explained by a complex combination of synthetic fertilizer load and industrial area upstream from the sampling point, the runoff index associated with it, and the mean river phosphate concentration in the site. Overall, the distribution of the phosphate patterns was hardly explained by the set of explanatory variables considered in this study; rather it was mainly explained by the presence of industrial areas upstream of the sampling points (Table 3 ). 


\section{Dynamic Factor Analysis \\ Factor Loadings}
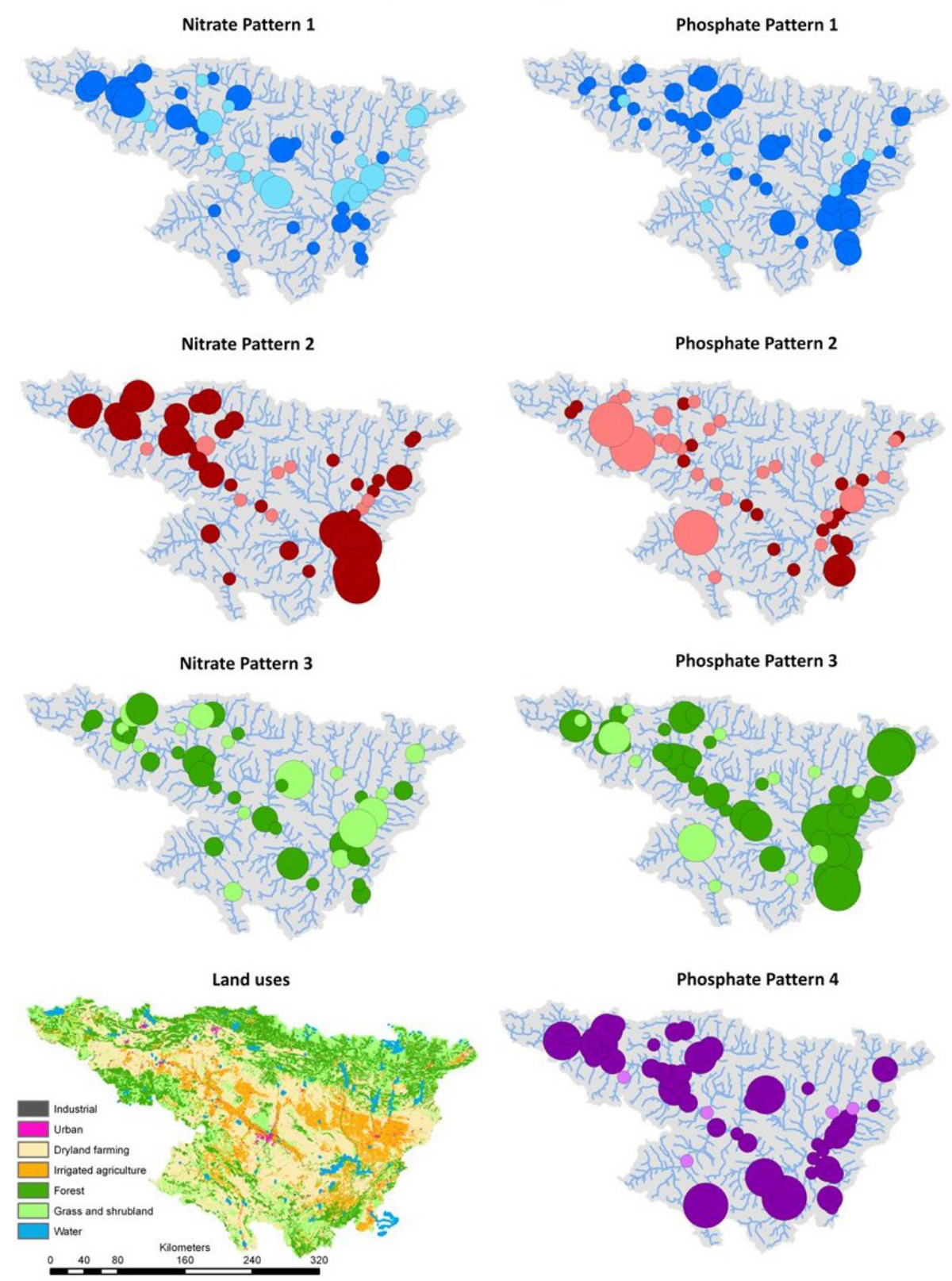

Figure 2. Factor loadings associated with nitrate patterns (left column) and phosphate patterns (right column). Dark circles indicate positive factor loadings and light-colored circles represent negative factor loadings. The size of the circles represents the magnitude of the factor loading at each monitoring point. A map with major land uses in the Ebro basin is enclosed in the lower left corner.

\subsection{The joint spatial distribution of the nutrient concentration patterns and explanatory factors}

The clustering analysis for the spatial distribution of the nitrate patterns and the significant explanatory variables found four aggregations among the 50 sampling sites (Fig. 3a). Cluster 1 contained sampling points located mainly in downstream sections of major tributaries of the Ebro River (par- ticularly along the Segre River); Cluster 2 included points in upstream locations of tributaries and in the main Ebro; Cluster 3 comprised points located even more upstream; and Cluster 4 collected the downstream sites of the main stem of the Ebro River. These clusters were characterized by significant differences in the absolute values of the factor loadings for Pattern 1 (Fig. 3b, non-parametric Wilcoxon test for mean comparison, $p=0.011)$ and Pattern $2(p=0.017)$. 
(a)

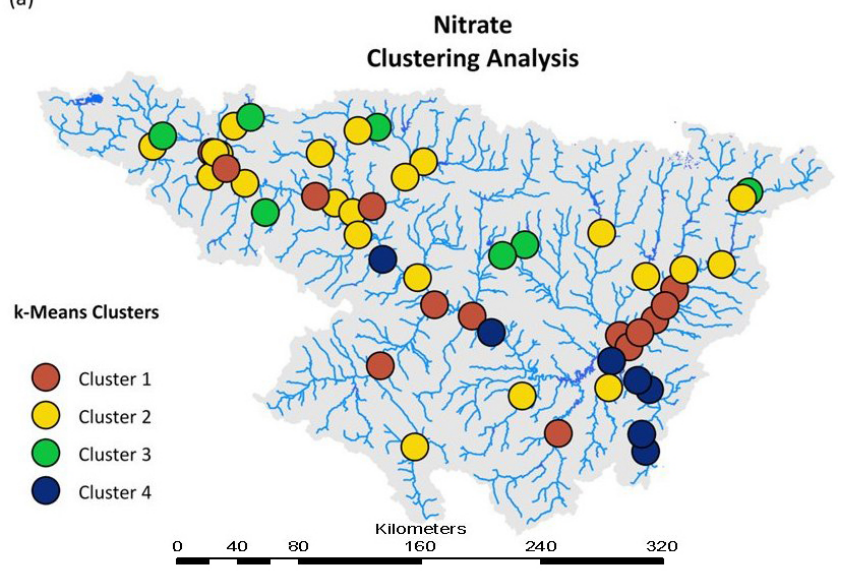

(b)

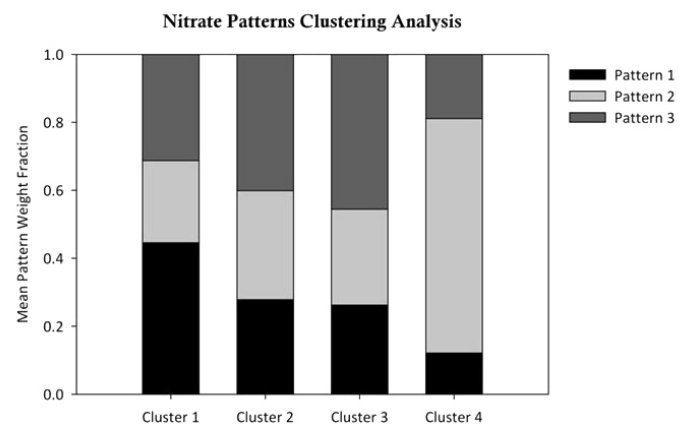

Figure 3. (a) Clustering analysis results for the spatial distribution of nitrate concentration patterns and associated explanatory variables. (b) Mean fraction of factor loadings (i.e., the overall weight of a specific pattern) found in each of the four clusters identified in the analysis.

Cluster 1 showed the largest relevance for Pattern 1, Cluster 4 for Pattern 2, and Cluster 3 for Pattern 3. Therefore the most fundamental regional difference in the dynamics of nitrate concentration in the basin was a switch from a streamflow-dominated dynamics in Cluster 1 to a reservoir biogeochemistry-dominated of Cluster 4 . The preeminence of Pattern 3 in Cluster 3 was also a significant spatial pattern extracted from the clustering analysis.

These differences between clustering groups were coincident with significant differences for many explanatory variables, particularly the extension of irrigated agriculture $(p<0.0001)$, the presence of reservoirs upstream the sampling point $(p<0.0001)$, and the application of synthetic fertilizers $(p<0.0001)$. Cluster 3 showed the minimum values for these variables, followed by Cluster 2 and Cluster 1, whereas Cluster 4 showed the largest values. Contrastingly, the clustering analysis for the phosphate concentration resulted in a poor regionalization with only two different aggregations (Fig. 4a), one including just five sampling points. There were no obvious spatial clusters beyond Cluster 2, which included points with higher values for Pattern 4 ( $p=$

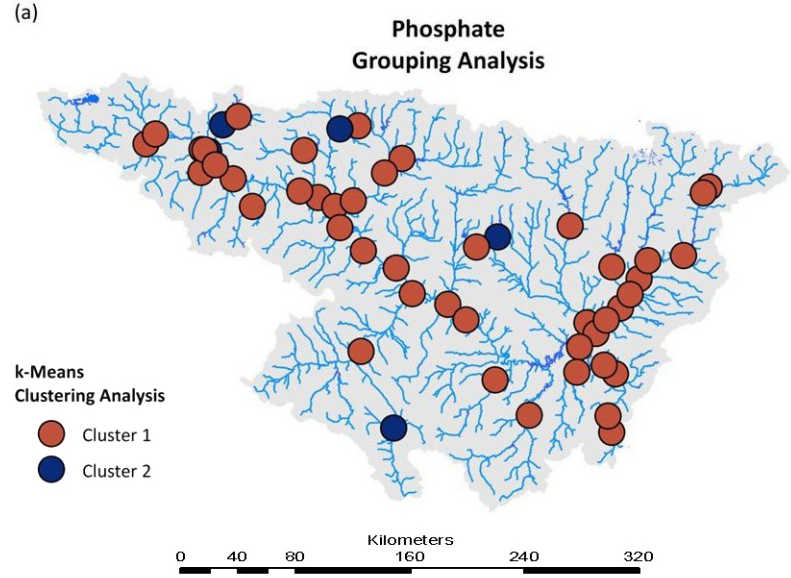

(b)

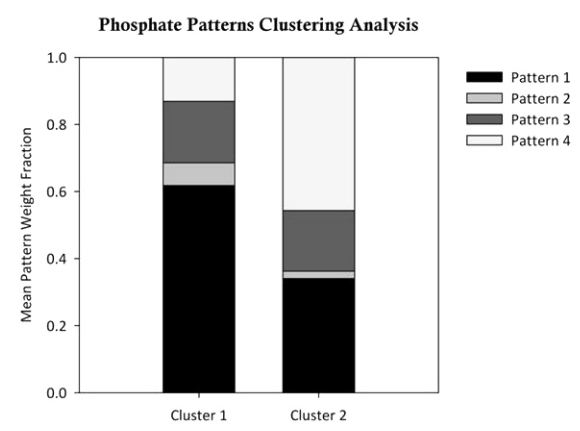

Figure 4. (a) Clustering analysis results for the spatial distribution of phosphate concentration patterns and associated explanatory variables. (b) Mean fraction of factor loadings (i.e., the overall weight of a specific pattern) found in each of the four clusters identified in the analysis.

$0.006)$. This coincided with very high phosphate concentrations $(p=0.002)$ and extensive industrial areas $(p=0.001)$ related to the sampling points. The poor regionalization in the phosphate case stressed again the apparently idiosyncratic behavior of phosphate concentration across sampling sites.

\section{Discussion}

\subsection{The nature of nutrient concentration patterns in the Ebro basin}

The analysis of the impacts of global change on freshwater ecosystems requires the use of appropriate tools to identify the main regional trends and modes present in hydrological and water quality variables. Results of this study show that the combination of DFA, traditional time series analysis, and regression methods is a convenient approach and several features of the time series shared by many sampling points across the Ebro basin can be detected.

The analysis of the nutrient concentration time series detected the existence of seasonal patterns related to hydrol- 

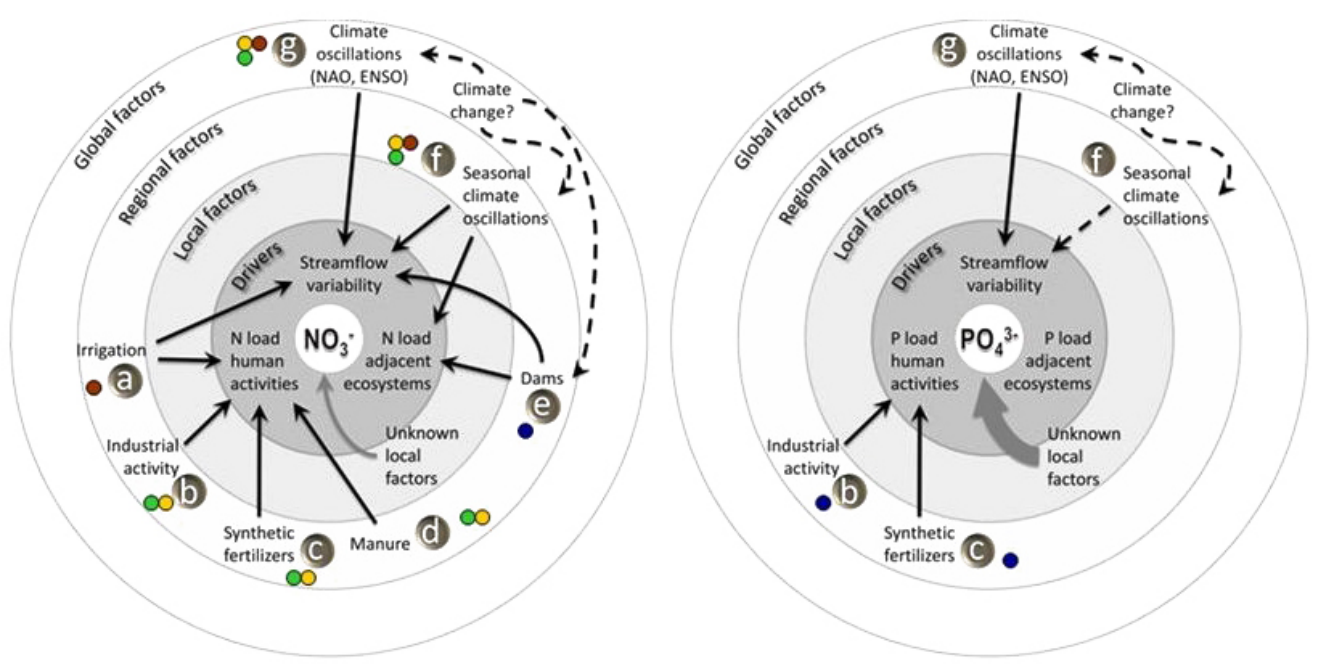

(a) Nitrate concentration switches from a concentration to a dilution dynamics with streamflow.

(b) Contributes to process a and favors the nitrate trends in the basin.

Helps defining the basic dilution dynamics explaining phosphate concentration patterns across the basin.

C The application of synthetic fertilizers hampers a background decreasing trend in nitrate concentration.

One of the main contributors to phosphorus loading at the regional scale.

d Areas with significant application of manure are prone to increasing trends in nitrate concentration.

(e) Nitrate delivered by dams overrides the nitrate dynamics associated to seasonal streamflow in downstream locations

f Climate seasonality define the basic annual pattern of nitrate related to streamflow and inputs from terrestrial ecosystems.

The association with phosphate concentration is weaker.

Low frequency oscillations in streamflow impact the dynamics of nitrate and phosphate concentration

Figure 5. Global change factors that, acting at different scales, contribute to shaping the spatiotemporal variability of nitrate and phosphate concentration in the Ebro basin. Lettered circles describe the relationship between nutrient concentration patterns and the identified factors and drivers of change. Colored circles in (a) nitrate and (b) phosphate link types of relationship to corresponding clusters (when applicable) displayed in Figs. 3 (nitrate) and 4 (phosphate), respectively.

ogy. Although the common hydrological relation with nutrient dynamics (Donner et al., 2002) may hide the detection of other seasonal cycles not related to streamflow, our analysis also detected seasonality that was unrelated to hydrology. While Pattern 1 of nitrate concentration was related to streamflow, the nitrate dynamics in the basin was also related to the phenological cycles of the adjacent terrestrial ecosystems or other water bodies upstream of each sampling point (Pattern 2). Terrestrial phenological processes such as those involved in leaf fall and decomposition would potentially be more important in upstream sections of the basin, where the biogeochemical activity in large reservoirs is not present. In the downstream section, in turn, the reservoir biogeochemical control on rivers and streams shaped Pattern 2 for nitrate concentration. The actual mechanism behind the association between nitrate concentration and air temperature may be complex, and in fact it may differ at different sampling points, since air temperature can co-vary with many other factors. In the case of nitrate concentration, assimilation by freshwater primary producers during summer (Carpenter and Dunham, 1985) and the seasonal evolution of leaf fall and decomposition (González, 2012) could have played a major role. However, other factors may contribute to lower concentrations, like the seasonal cycle of denitrification in the adjacent terrestrial ecosystems and upstream water bodies during summer months (Tatariw et al., 2013).

Nutrient concentrations showed multiple associations with streamflow spanning from the seasonal to the interannual scale. One of the most prominent features of nitrate concentration time series was the existence of a switching relationship with streamflow (expressed by the changing sign of factor loadings for Pattern 1). This implies a fundamental change of the dynamics of nitrate concentration and suggests a major change in the sources of nitrogen to freshwaters. The positive relationship between nutrient concentration and streamflow suggests the preponderance of diffusive inputs from the terrestrial ecosystems and non-irrigated agricultural fields, whereas the negative relationship pointed to a 
dilution mechanism typical of locations having point sources. The GLS models further identified the land fraction occupied by irrigated agriculture as the main factor associated with the presence of negative factors loadings for Pattern 1 of nitrate concentration. Summer irrigation is a common agricultural practice in Mediterranean areas that can disrupt the relationship with the natural flow regime as well as the nitrate dynamics. This has been already observed in the Ebro basin where the intra-annual $\mathrm{N}$ export differed among rainfed and irrigated crops, the former following the flow regime and the latter modifying it (Lassaletta et al., 2012). In addition, irrigation has the capability of altering local and regional precipitation behavior through changes in soil moisture and heat budgets (Boucher et al., 2004) particularly in downstream areas (Huber et al., 2014). However, none of these regional climate effects have been confirmed in the Ebro basin. The absence of seasonal relationships between nitrate concentration and streamflow (i.e., very low absolute values for Pattern 1) can also be related to the proximity to large reservoirs in the lower section of the basin, where the seasonal nitrate concentration cycles seem to be highly influenced by the water released from the reservoirs.

The supra-annual frequencies detected in the nitrate and phosphate concentration patterns in the Ebro point out to associations with climatic oscillations identified in the Mediterranean region. The North Atlantic Oscillation (NAO) has multiple modes starting at 1.4 years, while the El NiñoSouthern Oscillation (ENSO) has modes between 2.4 and 5.2 years (Rodó et al., 1997). Both the nutrient patterns and the streamflow series showed oscillations coherent with those from the ENSO and NAO, which are known to modify, through teleconnections, the magnitude and frequency of precipitation in a heterogeneous manner (Rodó et al., 1997). Furthermore, common air temperature patterns (shown in Sect. S.3. of Supplement) in the basin also showed significant frequencies between 2.2 and 5.7 years, which further confirms the relationship of meteorological conditions in the basin to the above-mentioned climatic modes.

The impact of ENSO on nitrate river concentrations is, in fact, not uncommon in areas under indirect ENSO effects, such as the SE United States (Keener et al., 2010). Moreover, the associations of ENSO with streamflow modifications (Marcé et al., 2010) and nitrate concentration dynamics (Vegas-Vilarrúbia et al., 2012) in the Iberian Peninsula have been unambiguously stated. Indeed, all nutrient concentration patterns showing significant supra-annual frequencies also showed significant relationships with streamflow in many sites across the basin. In our opinion, this indicates that the effect of atmospheric teleconnections on nitrate and phosphate concentrations was driven by modifications in the streamflow. Since streamflow relies on both precipitation and evapotranspiration, extreme events such as droughts and heat waves promoted by global atmospheric teleconnections can have significant effects on river water quality in the basin. Indeed, the relationship between the partially pre- dictable global climate modes and the occurrence and frequency of extreme events is a very active topic in the literature (Coumou and Rahmstorf, 2012) and their links with water quality crisis episodes should be further investigated, especially in the Mediterranean region, where climate extreme events are predicted to increase (García-Ruiz et al., 2011). Overall, the changes in these climatic modes within the 31 years included in our study could indicate the potential role of climate change in in-stream nutrient variability. Regarding long-term trends, no significant correlation was found between nutrients and climatic modes.

\subsection{Nutrient trends and local management practices}

The spatial distribution of the relevant patterns was identified by the magnitude of the factor loading for each pattern, and both results are obtained by means of DFA. Further cluster analyses including factor loadings as well as the corresponding significant explanatory variables provided further information about the spatial distribution and the dynamics of nutrient concentration patterns in the Ebro basin. The most remarkable spatial difference was the switch from streamflowdominated nitrate concentrations in upstream sections of the basin (Cluster 1) to nitrate concentrations being controlled by the biogeochemical activity of large reservoirs in downstream sections of the Ebro (Cluster 4). This switching dynamics was not evident in the phosphate analyses.

In the case of nitrate concentration, both decreasing and increasing trends were observed the basin. The association of the trends with sampling points affected by large loads of synthetic fertilizer (decreasing trend) and manure (increasing trend) indicates that nitrate trends were possibly promoted by the application of agricultural practices that, in the last 3 decades, can be associated with a more rational fertilizer application (Lassaletta et al., 2012). Also, the implementation of sewage treatment schemes in the basin can be partly invoked to justify this decrease (Romaní et al., 2010). The dominant role of nitrate concentration trends in the more upstream locations of the basin (mostly included in Cluster 3) suggest that the impact of human activities upstream sampling points were higher in headwater and small streams, and that these water courses and corresponding sub-basins were the most vulnerable to increasing nitrate trends. However, decreasing trends also dominated the time series in some of the sampling points included in Cluster 3, suggesting that upstream locations are also prone to improvement due to remediation measures and best-management practices. Particularly, our analysis suggests that the application of synthetic fertilizers precluded the existence of a decreasing trend in some areas of the basin, but the application of manure as a fertilizer actively promoted increasing nitrate concentration trends. This increasing nitrate trend was mainly observed in sampling points related to Cluster 1, particularly along the Segre River (NE of the basin). Overall, while manure application has dramatically grown in some specific areas during 
the last decades (Terrado et al., 2010), there has been a more rational application of synthetic fertilizers in the basin (Lassaletta et al., 2012).

The overall decrease of phosphate concentration in the Ebro basin since the early 1990s was highlighted by all four extracted patterns. This decreasing trend coincides with the improvement of urban sewage treatment in the most important cities of the Ebro basin (Ibáñez et al., 2008), since most patterns of phosphate dynamics derive from point sources. Furthermore, according to the same study by Ibáñez et al. (2008), there was a significant positive correlation between the decreasing phosphate concentration and decreasing total chlorophyll in the lower Ebro basin during the 1987-2004 period. The reduction of phosphate fertilizers in the agriculture could have also resulted in the reduction of phosphate loads exported to rivers and streams (BouzaDeaño et al., 2008). A similar pattern has been observed in the Loire River (France), where the wastewater treatment plants and the concurrent ban on phosphorus content in washing powders (Floury et al., 2012) were highly effective. Severe reductions of riverine phosphorus loads were common in Europe during the 1990s, while nitrate concentrations decrease has been limited to recent years (Ludwig et al., 2009). Overall, the significant trends identified in nitrate and phosphate concentration across the Ebro, whether increasing or decreasing, basin appear to be modulated by local management practices associated with the different anthropogenic activities that have co-existed in the basin during the study period, but no climatic factor seemed to play any relevant role in shaping decreasing or increasing trends of nutrient concentration.

\section{Conclusions}

Our results imply that the impact of global change on the dynamics of nitrate concentration across the Ebro basin is a multifaceted process that includes regional and global factors, while impacts on phosphate concentration depend more on local impacts and less on large-scale factors (Fig. 5). In the case of nitrate, our analyses have identified the presence of irrigated agriculture and its corresponding fertilization management practices (synthetic fertilizers or manure), the presence of industrial activities in the basin, and damming as the main global change factors. Other climatic processes linked to streamflow variability were also identified, but the impact of climate changes on these processes is uncertain and could not be disentangled in this study. These factors shape a complex dynamics including temporal trends and interannual and seasonal cycles, with either strong or vanishing relationships with streamflow, and links with phenological processes in upstream terrestrial ecosystems and downstream reservoirs. Interestingly, the impact of identified factors on this rich dynamic was not homogenous across the basin but clustered in four regions not entirely coherent from a geographic perspec- tive (Fig. 3). In contrast, phosphate concentration showed a more idiosyncratic behavior. The only relevant global change mechanism acting at large scales is the presence of industrial activities and the application of synthetic fertilizers, which defines higher phosphate concentrations in Cluster 2. The explanatory power of our models was low in the case of phosphate concentration dynamics, meaning that most variability was accounted by factors not considered in our models. Although these factors may include some relevant regional drivers, the contrasting results from the nitrate analysis imply that the ultimate reason of the lower performance of the phosphate models is the absence of the more local factors, such as the different timing of implementation of wastewater treatment technologies.

Overall, our analysis shows that nitrate concentration dynamics are more responsive to regional and global factors, while global change impacts on phosphate concentration dynamics operate at the small scales of point sources. Anthropogenic land uses seem to play the most relevant role, and appropriate fertilization management may aid in stabilizing temporal trends, thus avoiding future nitrate concentration increases. The relevance of the interannual signals in our nutrient concentration series suggest that any impact of climate change on the intensity and timing of global climate phenomena driving interannual streamflow oscillations can also exert a significant impact on river nutrient dynamics. This would be expressed more likely in variations of the prevalence of extreme events in streamflow that would impact nutrient dynamics. This may add to a multi-stressor situation typical from freshwaters in Mediterranean countries, guaranteeing future research on this topic.

\section{The Supplement related to this article is available online at doi:10.5194/bg-12-4085-2015-supplement.}

Acknowledgements. This study has been financially supported by the EU through the FP7 project GLOBAQUA (grant agreement no. 603629) and by the Generalitat de Catalunya (consolidated research group 2014 SGR 291-ICRA). It reflects only the authors' views. The community is not liable for any use that may be made of the information contained therein. R. Aguilera benefited from a doctoral grant (FI-DGR 2012) from the Catalan government.

Edited by: F. Wittmann

\section{References}

Argerich, A., Johnson, S. L., Sebestyen, S. D., Rhoades, C. C., Greathouse, E., Knoepp, J. D., Adams, M. B., Likens, G. E., Campbell, J. L., McDowell, W. H., Scatena, F. N., and Ice, G. G.: Trends in stream nitrogen concentrations for forested reference catchments across the USA, Environ. Res. Lett., 8, 014039, 2013. 
Barton, K.: MuMIn: Multi-model inference, R-Package, version 1.10.0, 2014.

Benítez-Gilabert, M., Alvarez-Cobelas, M., and Angeler, D. G.: Effects of climatic change on stream water quality in Spain, Clim. Change, 103, 339-352, 2010.

Bernal, S., Belillas, C., Ibáñez, J. J., and Àvila, A.: Exploring the long-term response of undisturbed Mediterranean catchments to changes in atmospheric inputs through time series analysis, Sci. Total Environ., 458, 535-545, 2013.

Boithias, L., Acuña, V., Vergoñós, L., Ziv, G., Marcé, R., and Sabater, S.: Assessment of the water supply:demand ratios in a Mediterranean basin under different global change scenarios and mitigation alternatives, Sci. Total Environ., 470/471, 567-577, 2014.

Boucher, O., Myhre, G., and Myhre, A.: Direct human influence of irrigation on atmospheric water vapour and climate, Clim. Dynam., 22, 597-603, 2004.

Bouza-Deaño, R., Ternero-Rodríguez, M., and FernándezEspinosa, A.J.: Trend study and assessment of surface water quality in the Ebro River (Spain), J. Hydrol., 361, 227-239, 2008.

Bovolo, C.I., Blenkinsop, S., Majone, B., Zambrano-Bigiarini, M., Fowler, H. J.; Bellin, A., Burton, A., Barceló, D., Grathwohl, P., and Barth, J.A.C.: Climate change, water resources and pollution in the Ebro Basin: Towards an integrated approach, in: The Ebro River Basin, edited by: Barceló, D. and Petrovic, M., Berlin Heidelberg, Springer-Verlag, 295-329, 2011.

Caille, F., Riera, J. L., and Rosell-Melé, A: Modelling nitrogen and phosphorus loads in a Mediterranean river catchment (La Tordera, NE Spain), Hydrol. Earth Syst. Sci., 16, 2417-2435, 2012 , http://www.hydrol-earth-syst-sci.net/16/2417/2012/.

Carpenter, E. J. and Dunham, S.: Nitrogenous nutrient uptake, primary production, and species composition of phytoplankton in the Carmans River Estuary, Long Island, New York, Limnol. Oceanogr., 30, 513-526, 1985.

Chang, H.: Spatial analysis of water quality trends in the Han River basin, South Korea, Water Res., 42, 3285-3304, 2008.

Cooper, S. D., Lake P. S., Sabater S., Melack, J. M., and Sabo, J. L.: The effects of land use changes on streams and rivers in mediterranean climates, Hydrobiologia, 719, 383-425, 2013.

Coumou, D. and Rahmstorf, S.: A decade of weather extremes, Nat. Clim. Change, 2, 491-496, 2012.

Cox, D. R. and Snell, E. J.: The analysis of binary data, London, Chapman and Hall, 1989.

Donner, S. D., Coe, M. T., Lenters, J. D., Twine, T. E., and Foley, J. A.: Modeling the impact of hydrological changes on nitrate transport in the Mississippi River Basin from 1955 to 1994, Global Biogeochem. Cy., 16, 1-18, 2002.

Estrada, F., Perron, P., Gay-García, C., and Martínez-López, B.: A Time-Series Analysis of the 20th Century Climate Simulations Produced for the IPCC's Fourth Assessment Report, Plos One, 8, 1-10, 2013.

Floury, M., Delattre, C., Ormerod, S. J., and Souchon, Y.: Global versus local change effects on a large European river, Sci. Total Environ., 441, 220-229, 2012.

Gallart, F., Delgado, J., Beatson, S. J. V., Posner, H., Llorens, P., and Marcé, R.: Analysing the effect of global change on the historical trends of water resources in the headwaters of the Llobregat and
Ter river basins (Catalonia, Spain), Phys. Chem. Earth, 36, 655661, 2011.

García-Ruiz, J. M., López-Moreno, J. I., Vicente-Serrano, S. M., Lasanta-Martínez, T., and Beguería S.:Mediterranean water resources in a global change scenario, Earth-Sci. Rev., 105, 121139, 2011.

Ghil, M., Allen, M. R., Dettinger, M. D., Ide, K., Kondrashov, D., Mann, M. E., Robertson, A. W., Saunders, A., Tian, Y., Varadi, F., and Yiou, P.: Advanced Spectral Methods for Climatic Time Series, Rev. Geophys., 40, 1-41, 2002.

González, E.: Seasonal patterns of litterfall in the floodplain forest of a large Mediterranean river, Limnetica, 31, 173-186, 2012.

Grimm, N. B., Faeth, S. H., Golubiewski, N. E., Redman, C. L., Wu, J., Bai, X., and Briggs, J. M.: Global Change and the Ecology of Cities, Science, 319, 756-760, 2008.

Grizzetti, B., Bouraoui, F., and Aloe, A.: Changes of nitrogen and phosphorus loads to European seas, Glob. Change Biol., 18, 769782, 2011.

Holmes, E. E., Ward, E. J., and Wills, K.: MARSS: Multivariate Autoregressive State-space Models for analyzing Time-series Data, The R Journal, 4, 11-19, 2012.

Holmes, E. E., Ward, E. J., and Wills, K.: MARSS: Multivariate Autoregressive State-Space Modeling, R-Package version 3.4, 2013.

Howarth, R. W., Sharpley, A., and Walker, D. Sources of nutrient pollution to coastal waters in the United States: Implications for achieving coastal water quality goals, Estuaries, 25, 656-676, 2002.

Huber, D. B., Mechem, D. B., and Brunsell, N. A.: The Effects of Great Plains Irrigation on the Surface Energy Balance, Regional Circulation, and Precipitation, Climate, 2, 103-128, 2014.

Ibáñez, C., Prat, N., Duran, C., Pardos, M., Munné, A., Andreu, R., Caiola, N., Cid, N., Hampel, H., Sánchez, R., and Trobajo, R.: Changes in dissolved nutrients in the lower Ebro river: causes and consequences, Limnetica, 27, 131-142, 2008.

Kang, S. and Lin, H.: Wavelet analysis of hydrological and water quality signals in an agricultural watershed, J. Hydrol., 338, 114, 2007.

Keener, V. W., Feyereisen, G. W., Lall, U., Jones, J. W., Bosch, D. D., and Lowrance, R.: El-Niño/Southern Oscillation (ENSO) influences on monthly $\mathrm{NO}_{3}$ load and concentration, stream flow and precipitation in the Little River Watershed, Tifton, Georgia (GA), J. Hydrol., 381, 352-363, 2010.

Kundzewicz, Z. W. and Krysanova, V.: Climate change and stream water quality in the multi-factor context: An editorial comment, Clim. Change, 103, 353-362, 2010.

Lane, L. J., Nichols, M. H., and Osborn, H. B.: Time series analyses of global change data, Environ. Pollut., 83, 63-68, 1994.

Lassaletta, L., García-Gómez, H., Gimeno, B. S., and Rovira, J. V.: Agriculture-induced increase in nitrate concentrations in stream waters of a large Mediterranean catchment over 25 years (19812005), Sci. Total Environ., 407, 6034-6043, 2009.

Lassaletta, L., Romero, E., Billen, G., Garnier, J., García-Gómez, H., and Rovira, J. V.: Spatialized N budgets in a large agricultural Mediterranean watershed: high loading and low transfer, Biogeosciences, 9, 57-70, doi:10.5194/bg-9-57-2012, 2012.

Lovett, G. M., Burns, D. A., Driscoll, C. T., Jenkins, J. C., Mitchell, M. J., Rustad, L., Shanley, J. B., Likens, G. E., and Haeuber, R.: 
Who needs environmental monitoring?, Front. Ecol. Environ., 5, 253-260, 2007.

Ludwig, W., Dumont, E., Meybeck, M., and Heussner, S.: River discharges of water and nutrients to the Mediterranean and Black Sea: Major drivers for ecosystem changes during past and future decades?, Prog. Oceanogr., 80, 199-217, 2009.

Marcé, R., Rodríguez-Arias, M. A., García, J. C., and Armengol, J.: El Niño Southern Oscillation and climate trends impact reservoir water quality, Glob. Change Biol., 16, 2857-2865, 2010.

Meybeck, M.: Global analysis of river systems: from Earth system controls to Anthropocene syndromes, Phil. Trans. R. Soc. Lond. B, 358, 1935-1955, 2003.

Milly, P. C. D., Dunne, K. A., and Vecchia, A. V.: Global pattern of trends in streamflow and water availability in a changing climate, Nature, 438, 347-350, 2005.

Parmesan, C. and Yohe, G.: A globally coherent fingerprint of climate change impacts across natural systems, Nature, 421, 37-42, 2003.

Pinheiro, J. C. and Bates, D. M.: Mixed effects models in S and S-PLUS, Springer, New York, 2000

Pinheiro, J. C., Bates, D. M., Debroy, S., Sarkar, D., and R Development Core Team: nlme: Linear and Nonlinear Mixed Effects Models, R-Package version 3.1-105, 2012.

Rabalais, N. N., Turner, R. E., Díaz, R. J., and Justic, D.: Global change and eutrophication of coastal waters, ICES J. Mar. Sci., 66, 1528-1537, 2009.

Rahim, K. and Burr, W.: multitaper: Multitaper spectral analysis tools, R-Package version 1.0-8, 2013.

Reshef, D., Reshef, Y., Finucane, H., Grossman, S. R., McVean, G., Turnbaugh, P. J., Lander, E. S., Mitzenmacher, M., and Sabeti, P. C.: Detecting novel associations in large datasets, Science, 334, 1518-1524, 2011.

Rodó, X., Baert, E., and Comín, F. A.: Variations in seasonal rainfall in Southern Europe during the present century: relationships with the North Atlantic Oscillation and the El Niño-Southern Oscillation, Clim. Dynam., 13, 275-284, 1997.

Romaní, A. M., Sabater, S., and Muñoz, I.: The Physical Framework and Historic Human Influences in the Ebro River, in: The Ebro River Basin, edited by: Barceló, D. and Petrovic, M., Berlin Heidelberg, Springer-Verlag, 1-20, 2010.

Rosenzweig, C., Karoly, D., Vicarelli, M., Neofotis, P., Wu, Q., Casassa, G., Menzel, A., Root, T. L., Estrella, N., Seguin, B., Tryjanowski, P., Liu, C., Rawlins, S., and Imenson, A.: Attributing physical and biological impacts to anthropogenic climate change, Nature, 453, 353-357, 2008.
Sabater, S. and Tockner, K.: Effects of Hydrologic Alterations on the Ecological Quality of River Ecosystems, in: Water Scarcity in the Mediterranean: Prospectives Under Global Change, edited by: Sabater, S. and Barceló, D., Berlin Heidelberg, Springer Verlag, 15-39, 2010.

Sabater, S., Feio, M. J., Graça, M. A. S., Muñoz, I., and Romaní, A.: The Iberian Rivers, in: Rivers of Europe, edited by: Tockner, K., Robinson, C., and Uhlinger, U., Academic Press, 113-149, 2009.

Tatariw, C., Chapman, E. L., Sponseller, R. A., Mortazavi, B., and Edmonds, J. W.: Denitrification in a large river: consideration of geomorphic controls on microbial activity and community structure, Ecology, 94, 2249-2262, 2013.

Terrado, M., Barceló, and D., Tauler, R.: Multivariate curve resolution of organic pollution patterns in the Ebro River surface watergroundwater-sediment-soil system, Anal. Chim. Acta, 657, 1927, 2010 .

Tilman, D., Fargione, J., Wolff, B., D’Antonio, C., Dobson, A., Howarth, R., Schindler, D., Schlensinger, W. H., Simberloff, D. and Swackhamer, D.: Forecasting Agriculturally Driven Global Environmental Change, Science, 292, 281-284, 2001.

US Global Change Research Act, in: Public Law 101-606(11/16/90) 104 Stat, 3096-3104, 1990.

Vegas-Vilarrúbia, T., Sigró, J., and Giralt, S.: Connection between El Niño-Southern Oscillation events and river nitrate concentrations in a Mediterranean river, Sci. Total Environ., 426, 446-453, 2012.

Vörösmarty, C. J., Mcintyre, P. B., Gessner, M. O., Dudgeon, D., Prusevich, A., Green, P., Glidden, S., Bunn, S. E., Sullivan, C. A., Reidy Liermann, C., and Davies, P. M.: Global threats to human water security and river biodiversity, Nature, 467, 555-561, 2010.

Woodward, G., Gessner, M. O., Giller, P. S., Gulis, V., Hladyz, S., Lecerf, A., and Chauvet, E. Continental-scale effects of nutrient pollution on stream ecosystem functioning, Science, 336, 14381440, 2012.

Yue, S., Pilon, P., Phinney, B., and Cavadias, G.: The influence of autocorrelation on the ability to detect trend in hydrological series, Hydrol. Proc., 16, 1807-1829, 2002.

Zuur, A. F., Fryer, R. J., Jolliffe, I. T., Dekker, R., and Beukema, J. J.: Estimating common trends in multivariate time series using dynamic factor analysis, Environmetrics, 14, 665-685, 2003.

Zuur A. F., Ieno E. N., and Smith G. M.: Analysing ecological data, New York, Springer, 2007. 